\title{
Post-impact mechanical characterisation of E-glass/basalt woven fabric interply hybrid laminates
}

\author{
I. M. De Rosa, F. Marra, G. Pulci, C. Santulli ${ }^{*}$, F. Sarasini, J. Tirillo, M. Valente \\ Sapienza - Università di Roma, Department of Chemical Engineering Materials Environment, Via Eudossiana 18 - 00184 \\ Rome, Italy
}

Received 22 September 2010; accepted in revised form 4 December 2010

\begin{abstract}
Post-impact properties of different configurations (symmetrical and non-symmetrical) of hybrid laminates including E-glass and basalt fibre composites, all with volume fraction of fibres equal to $0.38 \pm 0.02$ and manufactured by RTM, have been studied. With this aim, interlaminar shear strength tests and four-point flexural tests of laminates impacted with different energies $(0,7.5,15$ and $22.5 \mathrm{~J})$ have been performed. Acoustic emission (AE) localisation and AE evolution with applied flexural stress was studied to support impact damage characterisation, provided by SEM and transient thermography. The results indicate that a symmetrical configuration including E-glass fibre laminate as a core for basalt fibre laminate skins presents the most favourable degradation pattern, whilst intercalation of layers may bring to further improvement of the laminate properties, but also to more extended and complex damage patterns.
\end{abstract}

Keywords: polymer composites, mechanical properties, basalt fibres, acoustic emission, post-impact degradation

\section{Introduction}

In recent years, natural fibres, either extracted from plants, such as jute, flax, hemp, or of mineral origin, such as basalt, are increasingly proposed as a nontoxic and more easily recyclable alternative to glass fibres as a result of stricter environmental requirements. More specifically, the higher density of basalt fibres (about $2700 \mathrm{~kg} / \mathrm{m}^{3}$ ) is widely compensated by their higher modulus, excellent heat resistance, good resistance to chemical attack and to wear and low water absorption [1]. This suggests not only the possibility to apply them as a replacement for glass fibres, which has been the object of a previous study [2], but also the idea of making hybrids, able to combine, possibly with a positive global effect, the properties of both materials. As a matter of fact, hybridisation of basalt fibres has been attempted with ceramic fibres, to provide improved hot wear resistance to friction materials [3], and with high tensile strength fibres, such as carbon [4] and Kevlar [5]. In these cases, basalt provides a sufficient resistance, in particular to impact, even superior to that obtained by a possible substitution with glass fibres, coupled in particular with a substantial reduction in costs, with respect to carbon and Kevlar fibres. In the case of basalt/Nylon fibres hybrid laminates, low tensile modulus of Nylon is improved by adding basalt fibres, whilst nylon provides some more impact resistance [6].

In contrast, basalt hybridisation with glass fibres would imply using two fibres, which are chemically not very different: continuous basalt fibre has a not very different content in silica and alumina from glass fibres and also a comparable, if not superior, tensile strength [7]. A significant difference is their behaviour under corrosion: for basalt fibres, resistance to acids is much higher than that to alkalis, whilst for glass fibres resistance to acids is nearly

\footnotetext{
${ }^{*}$ Corresponding author, e-mail: carlo.santulli@uniroma1.it
} (c) BME-PT 
the same as that to alkalis [8]. This can for example make the former preferable over the latter for example in the automotive industry, where extensive use of acids is made. Moreover, basalt fibres, not containing additives in a single producing process, present an additional advantage in cost. Also, a previous study aimed at the comparison and discussion of the electrical properties of composites reinforced with basalt and E-glass woven fabrics, suggested that dielectric behaviour of the two composites in the frequency range $10 \mathrm{kHz}-1 \mathrm{MHz}$ is almost identical [9].

All the above findings would indicate that the combined use of basalt and glass fibres may have some scope: broadening the application field of the final material would also possibly result in a prospective reduced cost, without affecting its properties. It is significant, however, to assess that the composite presents a sufficient impact resistance to use it for structural components.

The major mode for impact damage absorption in basalt fabrics composites appears to be fibre breakage, delamination appearing less diffuse than in E-glass fibre composites [2,6]. Also, previous study suggested that in basalt fabrics composites and hybrids, crack propagation patterns during impact may be complex, if single layers are used in an interplay layout [5]. This damage complexity has the important consequence that it is not easy to directly find out whether the hybridisation produces a positive effect or not with respect to the original laminates, an indication which could be given e.g., by the rule of mixtures [10]. In this context, the measurement of post-impact residual strength becomes particularly important.

In this study, the different configurations, including symmetrical and asymmetrical glass/basalt laminates, are fully characterised using interlaminar shear strength tests and flexural tests. Impact damage is characterised from the study of post-impact flexural properties assisted by acoustic emission and thermography, visualising damage using scanning electron microscope (SEM) fractographs. This is carried out along the lines of two comparative studies between configurations of glass/jute fibre hybrid laminates, performed by the same research group [11-12] and in the aforementioned study about the comparison of E-glass and basalt fibre composites [2].

\section{Materials and methods}

The basalt (BAS 220.1270.P) and E-glass fabrics (RE 220P) were plain weave fabrics supplied by Basaltex-Flocart NV (Wevelgem, Belgium) and Mugnaini Group srl (Stiava-Massarosa, Italy), respectively. Both fabrics had the same specific surface weight $\left(220 \mathrm{~g} / \mathrm{m}^{2}\right)$. The matrix used was a Bisphenol-A epoxy based vinylester resin (DION 9102) produced by Reichhold, Inc (Research Triangle Park, North Carolina, USA). The hardener and accelerator were Butanox LPT (MEKP, 2 wt.\%) and NL-51P (Cobalt 2-ethylhexanoate, 1 wt.\%), respectively. The laminates were manufactured by a laboratory Resin Transfer Moulding (RTM) system described in [9]. From the laminates were removed the specimens for mechanical characterization.

All hybrid configurations, listed in Table 1, were produced using fourteen fabric layers and with a similar volume fraction, equal to $0.38 \pm 0.02$, so that the thickness of all the produced configurations was approximately the same. The fibre volume used was the maximum one, which allowed sufficient impregnation from the resin with the RTM system employed.

Four-point bending tests were performed in accordance with ASTM D 6272. Five specimens for each configuration type were tested, having the following dimensions: $150 \mathrm{~mm} \times 30 \mathrm{~mm} \times 3.1 \mathrm{~mm}(L \times W \times t)$. A span-to-depth ratio of $25: 1$ and a cross-head speed of $2.5 \mathrm{~mm} / \mathrm{min}$ were used. Strain gauges were used to evaluate the flexural modulus. The specimens were loaded in tension either as received or following impact with energies of 7.5, 15 and 22.5 Joules, applied as described below. It is suggested that most part of impact damage, even with the highest energy applied, which does not result in the full penetration of the laminate, should be contained in the width of the specimen. The interlaminar shear strength was evaluated in accordance with ASTM D 2344. Ten specimens were tested for each laminate, having the following dimensions: $20 \mathrm{~mm}$ $\times 6.2 \mathrm{~mm} \times 3.1 \mathrm{~mm}(L \times W \times t)$. A span-to-depth ratio of $4: 1$ and a cross-head speed of $1 \mathrm{~mm} / \mathrm{min}$ were used. The mechanical characterization was performed on a Z010 universal testing machine by Zwick/Roell (Ulm, Germany) equipped with a $10 \mathrm{kN}$ load cell.

Glass/basalt hybrid specimens were impacted and then subjected to post-impact four-point bending 
Table 1. Hybrid laminates configurations

\begin{tabular}{|c|c|c|c|}
\hline Configuration & Layup sequence & $\begin{array}{c}\text { Basalt layers } \\
\text { (avg. vol.\% fibres) }\end{array}$ & $\begin{array}{c}\text { E-glass layers } \\
\text { (avg. vol.\% fibres) }\end{array}$ \\
\hline B & $14 \mathrm{~B}$ & $14(38 \%)$ & - \\
\hline $\mathrm{V}$ & $14 \mathrm{~V}$ & - & $14(38 \%)$ \\
\hline $\mathrm{VBV}$ & $3 \mathrm{~V} / 8 \mathrm{~B} / 3 \mathrm{~V}$ & $8(22 \%)$ & $6(16 \%)$ \\
\hline $\mathrm{BVB}$ & $3 \mathrm{~B} / 8 \mathrm{~V} / 3 \mathrm{~B}$ & $6(16 \%)$ & $8(22 \%)$ \\
\hline $\mathrm{BVBV}$ & $(1 \mathrm{~B} / 1 \mathrm{~V} / 1 \mathrm{~B} / 1 \mathrm{~V} / 1 \mathrm{~B} / 1 \mathrm{~V} / 1 \mathrm{~B})_{\mathrm{s}}$ & $7(19 \%)$ & $7(19 \%)$ \\
\hline
\end{tabular}

tests, using five samples per configuration and impact energy. Impact tests were performed on an instrumented impact tower fitted with an antirebound device. The impact point was located at the centre of the specimens. The impact energy was changed varying the mass of the hemispherical drop-weight striker $(\varphi=12.7 \mathrm{~mm})$, thus keeping a constant velocity of $2.5 \mathrm{~m} / \mathrm{s}$, obtaining energies of 7.5, 15 and $22.5 \mathrm{~J}$.

Post-impact flexural tests were monitored by acoustic emission until final fracture occurred using an AMSY-5 AE system by Vallen Systeme GmbH (Icking, Munich, Germany). The AE acquisition settings used throughout this experimental work were as follows: threshold $=35 \mathrm{~dB}$, Rearm Time $(R T)=$ $0.4 \mathrm{~ms}$, Duration Discrimination Time $(D D T)=0.2$ $\mathrm{ms}$ and total gain $=34 \mathrm{~dB}$. This level of threshold was selected after 30 minutes recording of the background noise with the AE setup configuration actually used, and was set $6 \mathrm{~dB}$ above the maximum level of the recorded spurious signal from the electronic system. The PZT AE sensors used (code SE150-M by DECI, Midland, Texas, USA) were resonant at $150 \mathrm{kHz}$. The sensors were placed on the surface of the specimens at both ends to allow linear localization.

After impact, the damaged area was observed using an Avio/Hughes Probeye TVS 200 (Cinisello Balsamo, Italy) thermal video system. The heating was obtained using a $500 \mathrm{~W}$ lamp: a 5 s pulse was applied, positioning the lamp at approximately $200 \mathrm{~mm}$ from the sample, so that a maximum temperature of $35^{\circ} \mathrm{C}$ was obtained on the sample surface. The cooling transient period was not long enough to allow images acquisition, so that the thermograms were acquired between 2 and $5 \mathrm{~s}$ during heating. The emissivity was set at 0.90 when the surface illuminated was in basalt and at 0.15 when it was in glass: these values were deemed offering in both cases images with the best contrast with the background. The variations of temperature on the specimen sur- face were mainly ascribed to geometry alterations produced by impact damage, since both these composites show poor conductivity.

The microstructural characterization was carried out by scanning electron microscopy (SEM) using a Philips XL40 (Eindhoven, Netherlands). Prior to all SEM observations, the specimens were sputtered with gold to prevent charging.

\section{Results}

\subsection{Mechanical properties}

The principal purpose of adding basalt fibre laminates to E-glass fibre laminates would be getting a final laminate which, in spite of a slight weight penalty, has better mechanical properties, both as received and after impact. A previous study [2] demonstrated that non-impacted basalt fibre reinforced laminates show interlaminar shear strength and flexural properties slightly superior to those of E-glass fibre reinforced laminates. Here, in the VBV laminate, which includes the lowest number of basalt fibre layers among the three configurations, adding them does not result in an improvement of interlaminar shear strength over pure E-glass fibre reinforced laminates (Figure 1). The other two configurations, BVB and BVBV, present values of the interlaminar shear strength which are intermediate between E-glass fibre and basalt fibre reinforced laminates.

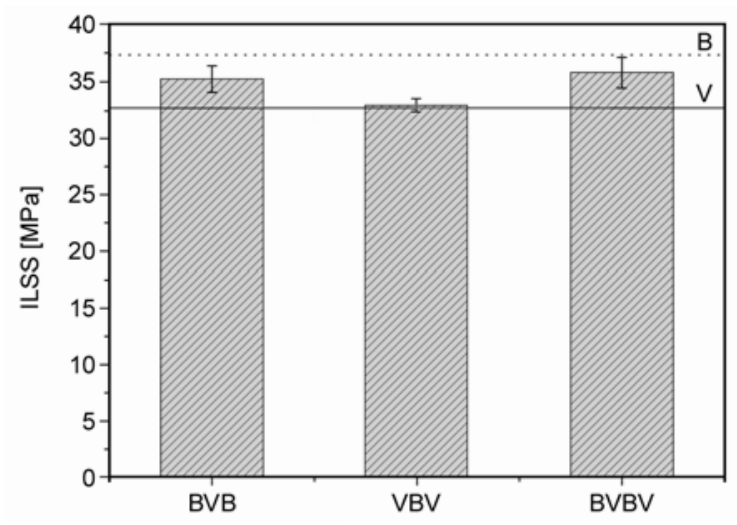

Figure 1. Interlaminar shear strength of the different hybrid laminates 

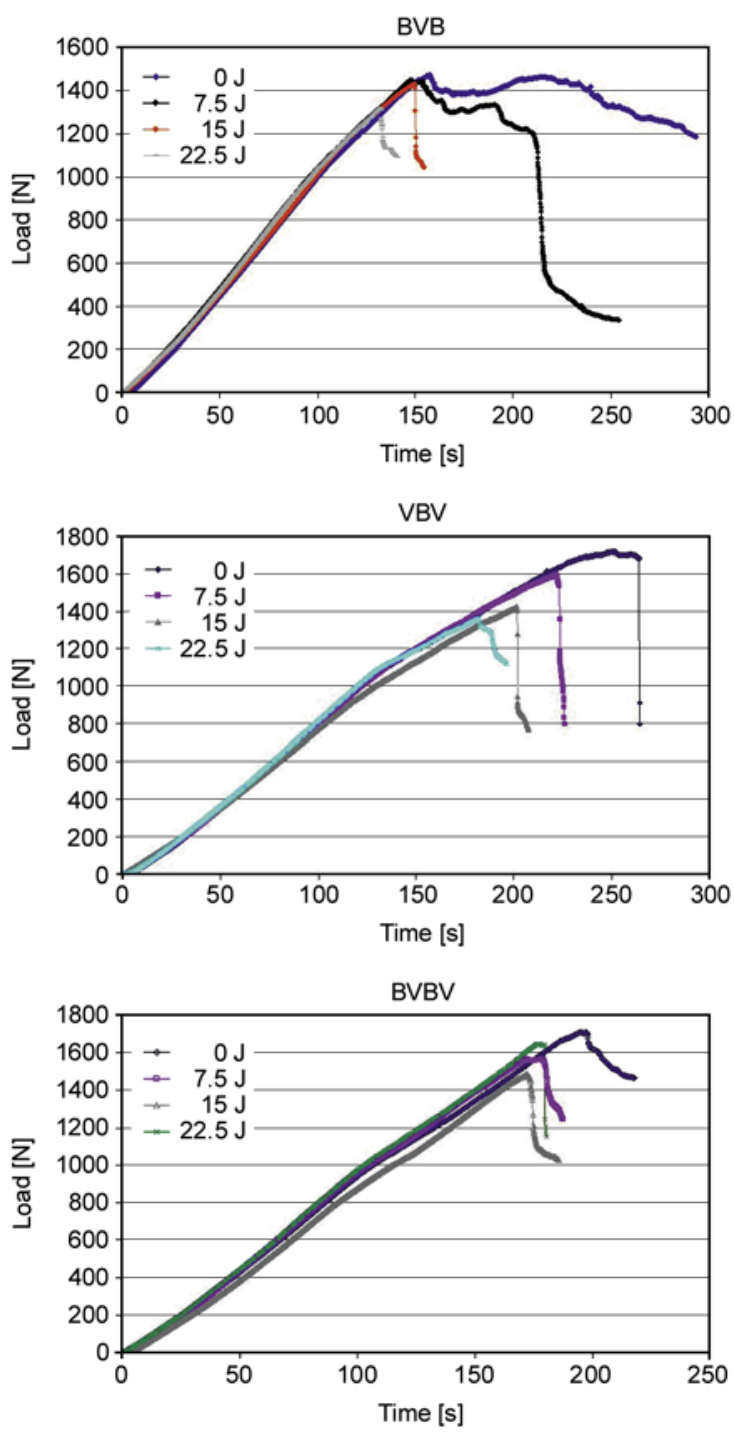

Figure 2. Typical flexural curves for hybrid laminates impacted at $0,7.5,15$ and $22.5 \mathrm{~J}$

As regards the study of degradation of flexural properties with increasing impact energies, typical flexural curves of non-impacted and impacted hybrid laminates of all configurations are shown in Figure 2. The main difference which may be observed is that BVB hybrids, when non-impacted or impacted at the lowest energy, show a more gradual failure process than the other hybrids. Impact reduces the flexural strength in a more variable way among the different configurations than it does with flexural modulus (compare Figure 3 and 4). In particular, in Table 2 all configurations are ranked from the higher to the lower flexural strength, including also the pure E-glass and basalt fibre reinforced laminates. The larger degradation of flexural strength of VBV laminates with growing impact energy is clearly observable, whilst in general BVBV appears

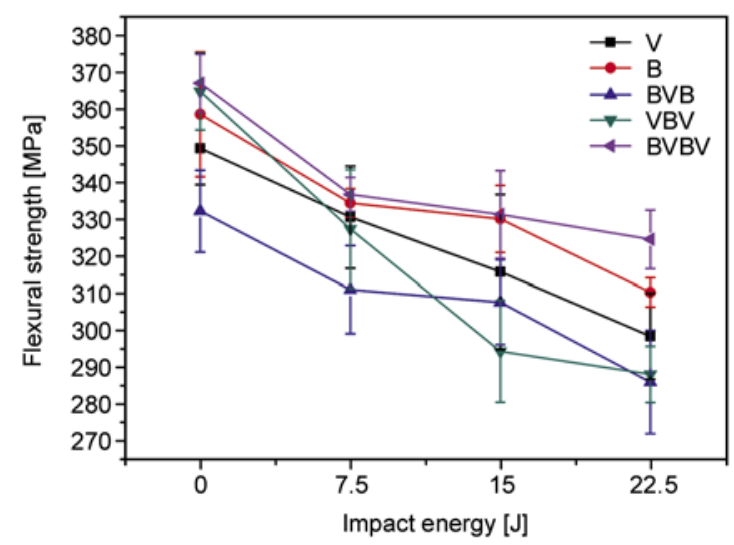

Figure 3. Post-impact flexural strength of the different laminates (compared with pure E-glass, V, and pure basalt fibre laminates, B)

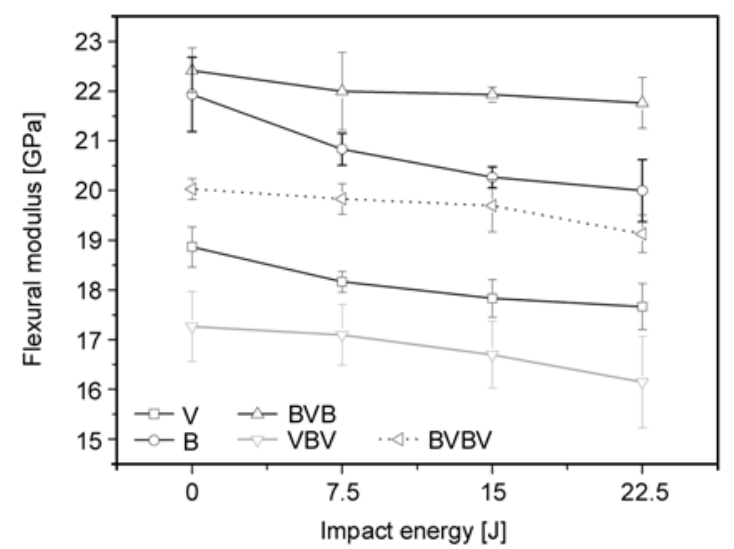

Figure 4. Post-impact flexural modulus of the different laminates (compared with pure E-glass, V, and pure basalt fibre laminates, B)

Table 2. Laminates ordered from maximum to minimum flexural strength at different impact energies

\begin{tabular}{|c|l|l|l|l|}
\hline Position & \multicolumn{1}{|c|}{$\mathbf{~ J}$} & $\mathbf{7 . 5} \mathbf{J}$ & $\mathbf{1 5} \mathbf{J}$ & $\mathbf{2 2 . 5} \mathbf{J}$ \\
\hline 1 & BVBV & BVBV & BVBV & BVBV \\
\hline 2 & VBV & B & B & B \\
\hline 3 & B & V & V & V \\
\hline 4 & V & VBV & BVB & VBV \\
\hline 5 & BVB & BVB & VBV & BVB \\
\hline
\end{tabular}

in all cases the best laminate configuration in this respect. As regards flexural modulus (Figure 4), BVB and VBV laminates give at all impact energies the higher and lowest performance of all configurations, respectively: it is also to be noted that all laminates show comparable levels of degradation. The average residual flexural strength of impact damaged specimens normalized to that of undamaged ones is reported in Figure 5. This figure aims at clarifying which is the average level of degradation which is to be expected in every laminate as an 


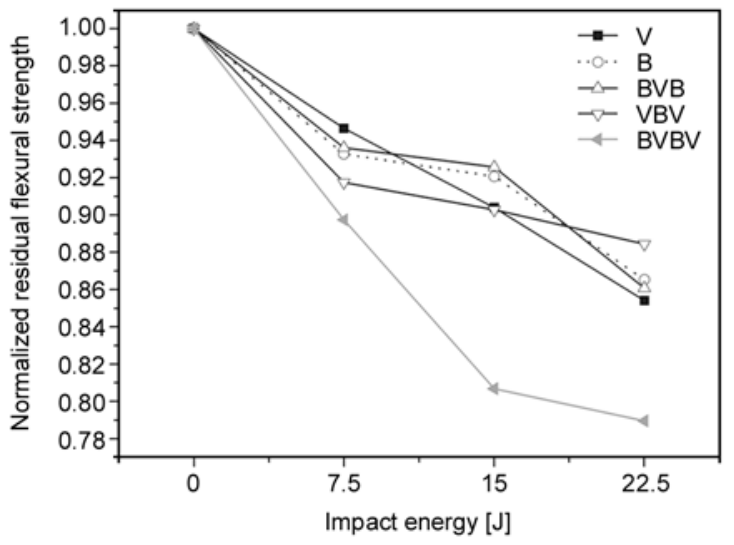

Figure 5. Normalised residual flexural strength of the different laminates (compared with pure E-glass, V, and pure basalt fibre laminates, B)

effect of impact damage with respect to the same laminate before the impact event. Here again, the lowest residual properties are shown by VBV laminates.

\subsection{Acoustic emission analysis}

Prior to the acoustic emission analysis, the measurement of the wave propagation speed in the laminates has been performed within an accuracy of $\pm 10 \mathrm{~m} / \mathrm{s}$, as allowed by the AE system on the distances involved. The values obtained are reported in Table 3. It can be noticed as the difference among values obtained for the three hybrid laminates can be considered within the statistical variability of the measurement.

As a preliminary consideration, from AE cumulative counts vs. time curves it is possible to identify an approximate load where acoustic emission activity starts. In particular, neglecting sparse low-counts events, which may take place even at very low load, acoustic emission is considered to commence when it starts to be visible from AE cumulative counts vs. time graphs, referred to the whole test, an example of which is given in Figure 6. This happens when AE counts exceed approximately $1 / 500$ of the final cumulative counts: at this point, an AE start load is measured. This derives empirically from the maximum achievable end-of-scale of the graph on the

Table 3. Wave propagation speed of the laminates $[\mathrm{m} / \mathrm{s}]$

\begin{tabular}{|c|c|}
\hline Laminate & Wave propagation speed $[\mathbf{m} / \mathbf{s}]$ \\
\hline B & 3970 \\
\hline V & 3660 \\
\hline BVB & 3800 \\
\hline VBV & 3840 \\
\hline BVBV & 3780 \\
\hline
\end{tabular}

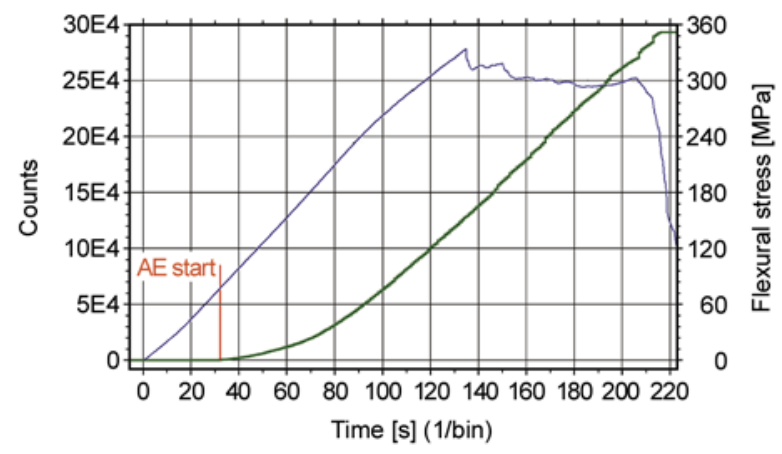

Figure 6. AE start load measured from cumulative counts vs. time curve (in green) and the corresponding flexural stress vs. time curve (in blue) (BVB hybrid laminate impacted at 7.5 Joules)

Y-axis (1654 pixels), and the fact that only a gradient of not less than three pixels starts being visible. Beyond the AE start load, AE activity during monotonic loading is likely to grow with increasing stress, although the specific characteristics of such behaviour may change considerably depending on materials properties and presence of irreversible damage. To better clarify these characteristics, the tests have been divided in five phases, according to the load levels, from 0 to $25 \%, 25$ to $50 \%, 50$ to $75 \%$, and 75 to $100 \%$ of the maximum load. The fifth phase is denominated as 'post' and represents those AE events detected after reaching the maximum load, when the load decreases in the immediate proximity of failure. The phases are reported on a typical flexural loading curve in Figure 7.

A further analysis of AE data is performed on their location with respect to impact (if any): the centre of the impacting head corresponds to the midpoint between the edge of the two sensors (located at abscissa 15 and $135 \mathrm{~mm}$, respectively), at the abscissa $x=75 \mathrm{~mm}$. With respect to their locations, the events are divided in four classes, namely A, for those detected within the impacted length $(68-81 \mathrm{~mm})$,

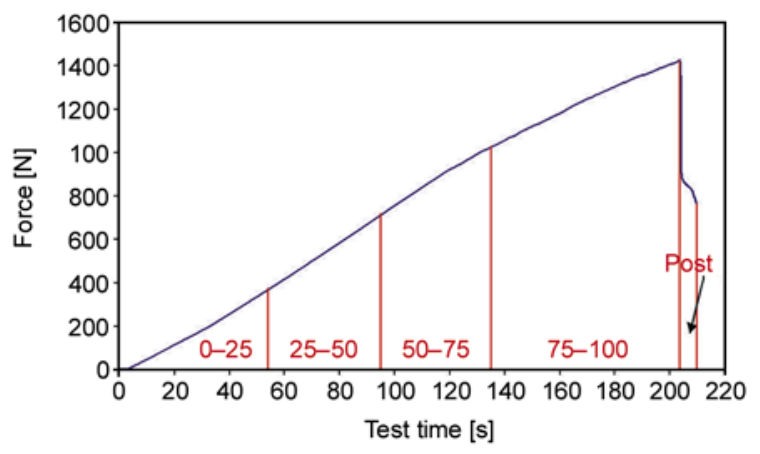

Figure 7. Load levels on a typical flexural load vs. time curve (VBV hybrid laminate impacted at 15 Joules) 
$\mathrm{B}$, detected in a location displaced by no more than one impacted length from either of the extremes of A (55-68 and 81-94 mm), C, detected in the remaining part of the laminate between the sensor edges (15-55 and $94-135 \mathrm{~mm}$ ), and $\mathrm{D}$, detected under the sensors and outside them (0-15 and 135- $150 \mathrm{~mm})$. More specifically, the localisation analysis is aimed at discerning on impacted samples between the two principal modes of impact damage. These represent the indentation mode, which is limited to the area in physical contact with the impacting head ('A' class of $\mathrm{AE}$ events), and the delamination mode, which has been approximated for low impact energies with a ring-shaped area extending no further than twice the impacting head diameter from the centre ('B' class of AE events). Other events detected in the bulk of the laminate between the sensors are in the 'C' class, whilst those very close to the laminate's edge, which can be supposed to be mostly unrelated with fracture events, are in the 'D' class. An example of the distribution between the four classes is reported using different colours in Figure 8.

Results in Figure 9, concerning stress where acoustic emission activity starts, indicate that for nonimpacted laminates, the worst performance is obtained with VBV laminates, which are supposed to be slightly less tolerant to pure flexural loading. In the laminates impacted with the lowest energy $(7.5 \mathrm{~J})$, acoustic emission may initiate later during loading (in particular, this happens on VBV and with lesser evidence on BVB hybrids). This is likely to suggest that the limited depth and gravity of impact damage is not yet sufficient to trigger further crack growth and delamination in the laminates, as an effect of flexural loading, rather making the material less sensitive to it.

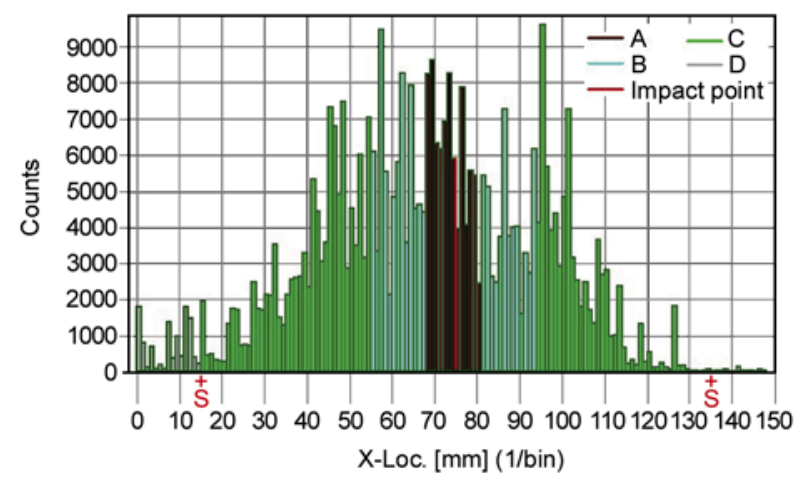

Figure 8. Partition of the events according to their location along the laminate (BVBV laminate impacted at $22.5 \mathrm{~J})$ (letter $\mathrm{S}$ indicates sensors location)

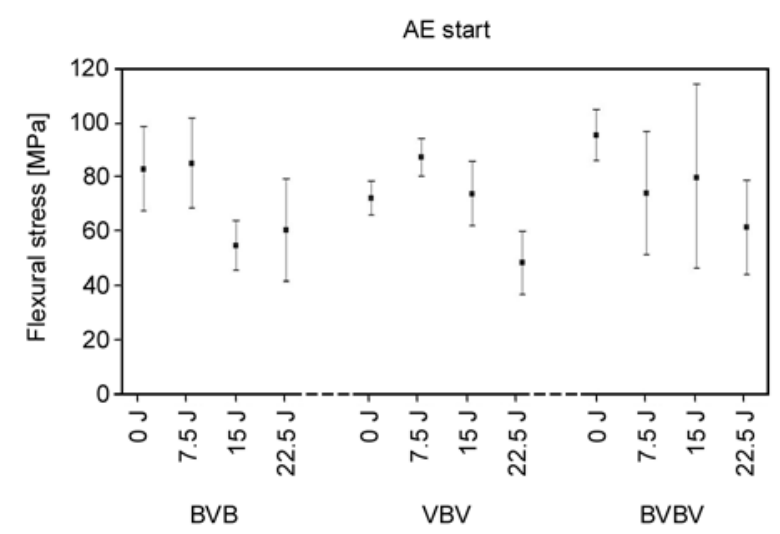

Figure 9. AE start stress $[\mathrm{MPa}]$ for all hybrid laminate configurations

A significant degradation of properties occurs with impact at $22.5 \mathrm{~J}$ for VBV laminates and both at 15 and $22.5 \mathrm{~J}$ on BVB laminates: here AE start is around $55 \mathrm{MPa}$, compared with $80 \mathrm{MPa}$ for the nonimpacted BVB laminates. A large scattering in performance is observed for BVBV laminates, which may be the result of the variable adhesion between the different interfaces between glass and basalt fibre layers in the laminates.

The results obtained from the study of the evolution of acoustic emission activity with load are reported in Figure 10. This analysis can be considered quite reliable in that the patterns of flexural load vs. time curve does not change much between hybrids (see Figure 2) (apart from some differences on BVB hybrids at 0 and $7.5 \mathrm{~J}$ ). The main indication from Figure 9 are that the typical trend of increased AE detection with growing load is more frequently disturbed here than it was on pure E-glass or basalt laminates. In particular, it can be noticed that there is a strongly variable normalised count rate in the final part of the test when the applied stress goes beyond the quasi-elastic limit. In general, it is suggested, by comparison with what observed on pure basalt or E-glass fibre laminates in [2], that whenever the growing trend of acoustic emission is preserved (such as for example is the case for VBV laminates impacted at 15 and especially $22.5 \mathrm{~J}$ ), damage progression which produces acoustic emission takes place preferentially in one of the two laminates. In contrast, when no clear trend is observable, it is possible that both E-glass and basalt fibre laminate forming the hybrids are damaged in a comparable way (this happen e.g., in all BVB laminates, with exception of the $22.5 \mathrm{~J}$ impacted ones). 

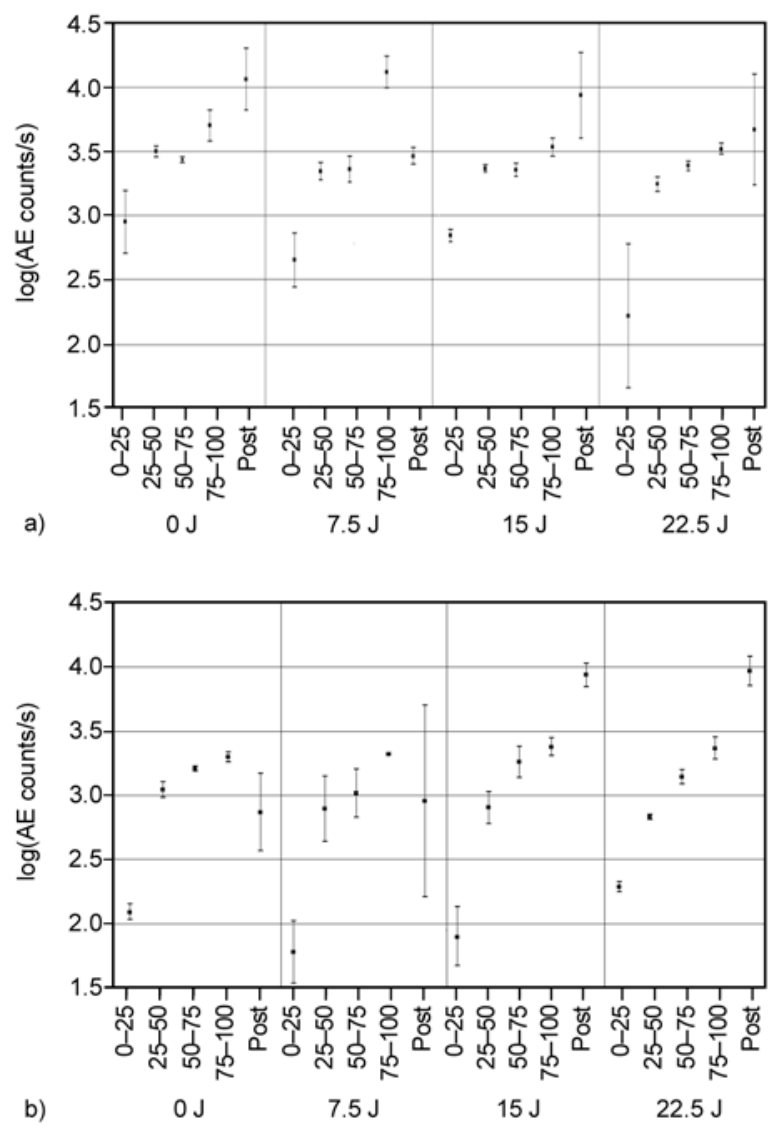

b)

$0 \mathrm{~J}$

15

$22.5 \mathrm{~J}$

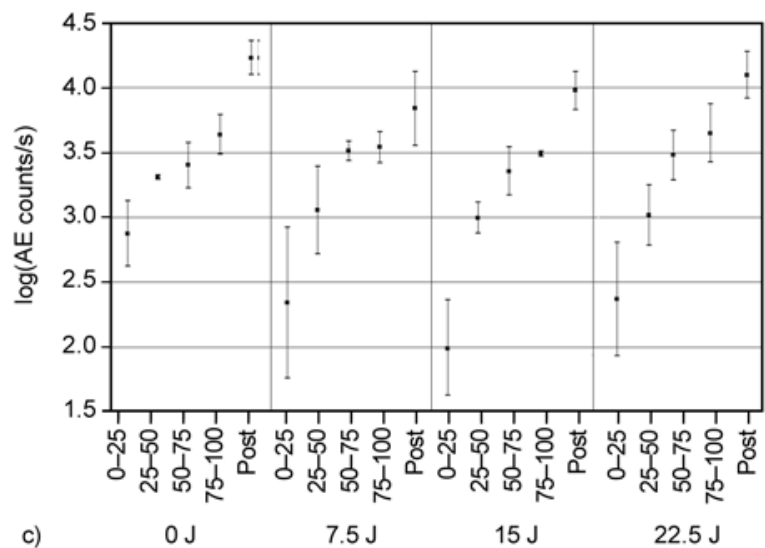

Figure 10. a) AE log (Count rate over time) vs. load for BVB hybrid laminates; b) AE log (Count rate over time) vs. load for VBV hybrid laminates; c) AE log (Count rate over time) vs. load for BVBV hybrid laminates

AE location analysis (Figure 11) indicates that there are more B-class than A-class normalised events for impacted BVB laminates, whilst the opposite is true for impacted VBV laminates: this suggests that in the former case most critical damage is in the wider delaminated area, whilst in the latter it is in the immediate vicinity of the impact centre, in a belt whose length corresponds to the impactor diameter.
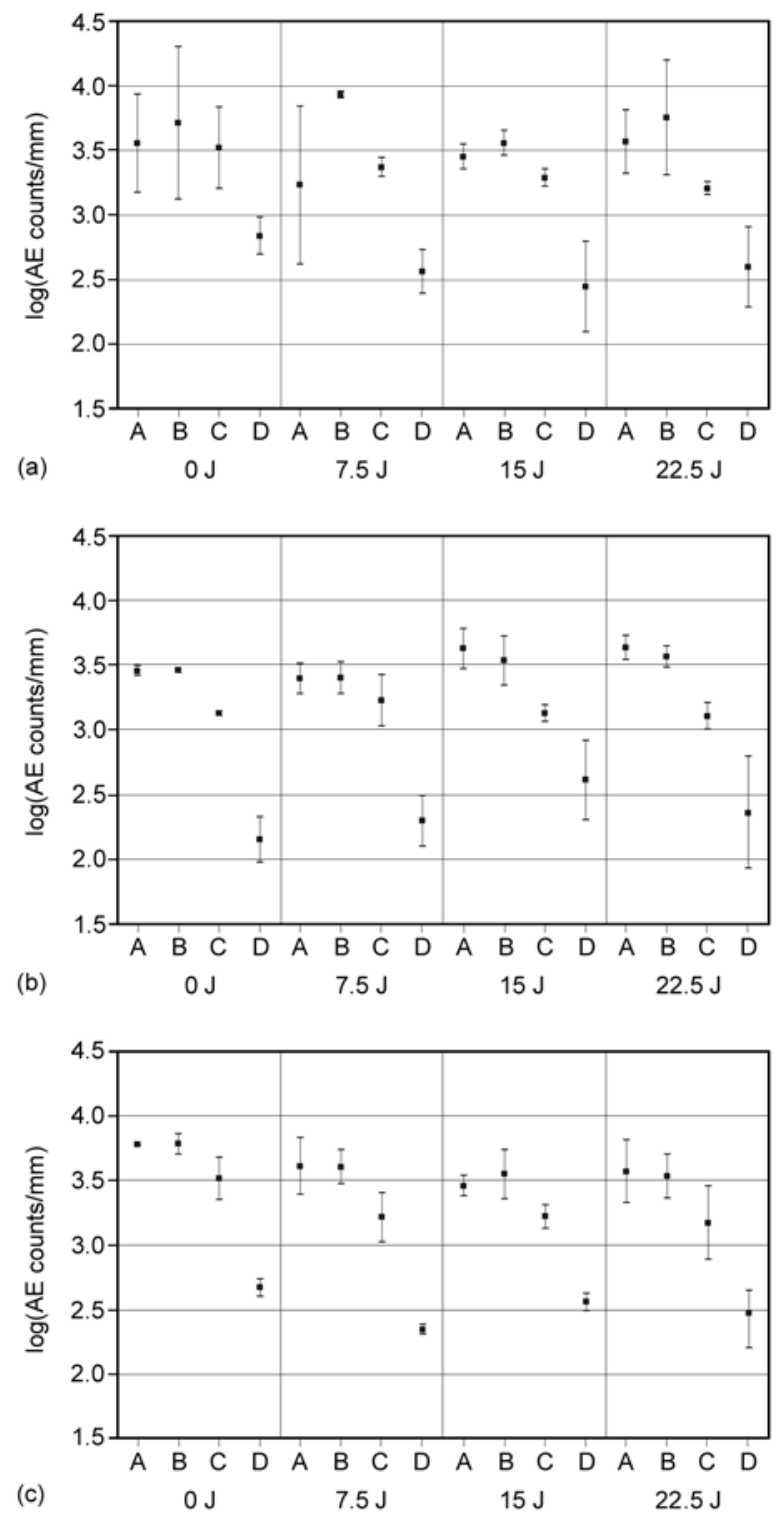

Figure 11. a) AE log (Count rate over distance) vs. X-location for BVB hybrid laminates; b) AE log (Count rate over distance) vs. X-location for VBV hybrid laminates; c) AE log (Count rate over distance) vs. X-location for BVBV hybrid laminates

For BVBV laminates, an intermediate situation between the two is revealed.

\subsection{Impact damage characterisation}

Impact damage characterisation was carried out on laminates which are larger than those necessarily used for post-impact flexural tests. This allowed clarifying whether damage produced by applying these impact energies was effectively contained in the width of flexural specimens. This is more often than not the case, with exceptions for the 22.5 Joules impacted laminates. In Figure 12 are represented 

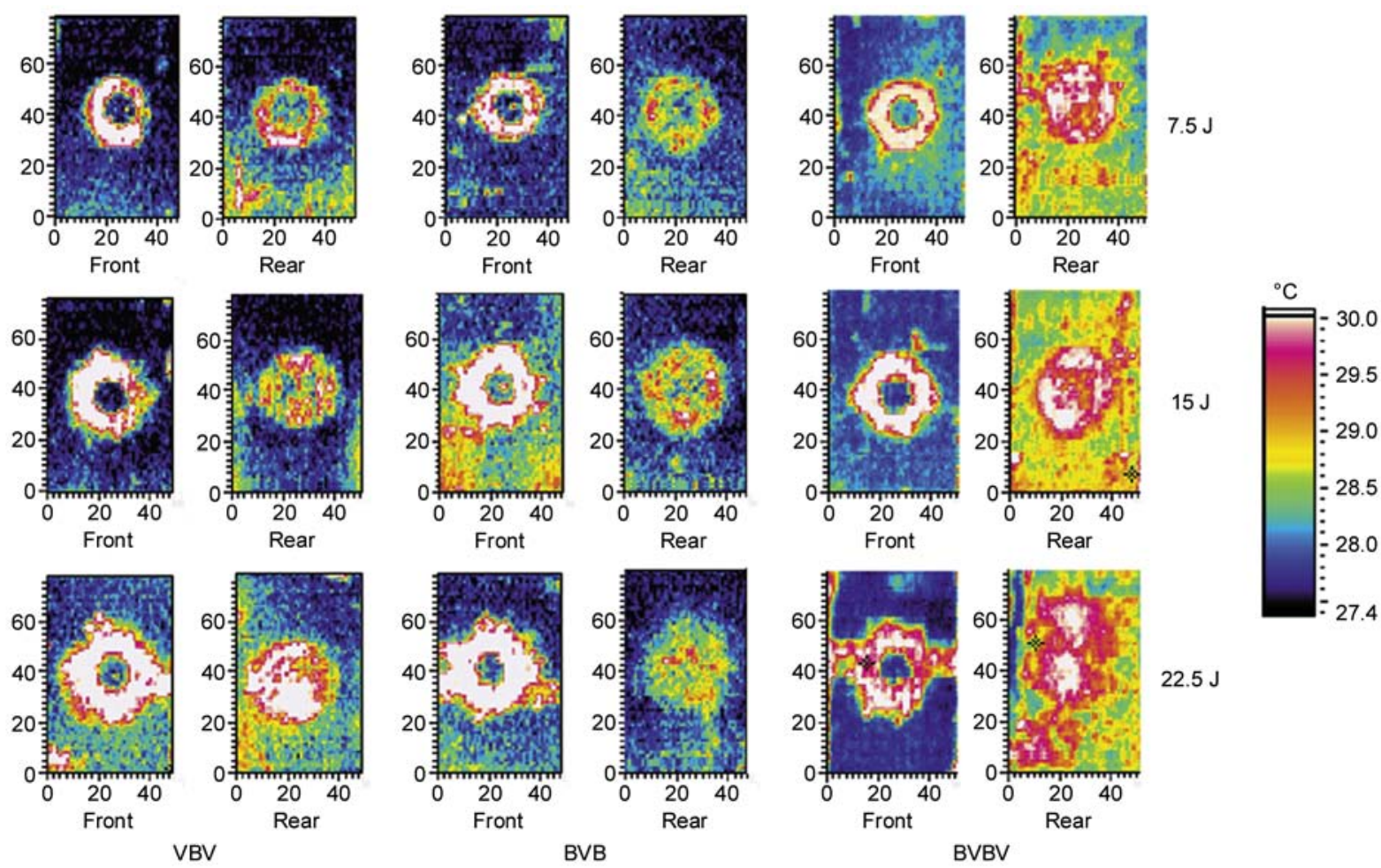

$22.5 \mathrm{~J}$

Figure 12. IR thermograms of both surfaces of the impacted laminates (dimensions are given in mm)

the impacted and non-impacted surfaces of the hybrid laminates at the different impact energies, as obtained using pulsed IR thermography: a region with dimensions $75 \times 45 \mathrm{~mm}$ is shown in the images. As a general consideration, the visualisation of the impacted area was easier whenever a basalt fibre laminate is observed, due to its high emissivity. In contrast, in some cases on the glass fibre reinforced laminates the weaving structure created some disturbance to the thermographic signal. In particular, the difficulties of observing impact damage on Eglass fibre reinforced laminates using IR thermography have been recently reported in [13]. The measurements suggest that at 7.5 and $15 \mathrm{~J}$ the dimension of the impact damaged area for all laminates is comparable. At $22.5 \mathrm{~J}$ all laminates appear heavily damaged in most of their mid-section corresponding to the impact line. However, whilst BVBV laminates show a more symmetrical delamination area, clearly extending towards both edges, the other two laminates show a more unpredictable damage progression. This may occur either preferentially in the direction of one of the edges, as is the case for VBV laminates, or in other random directions, as it happens with BVB laminates. The presence of dissymmetric damage does suggest in general that stiffness degradation consequent to impact affects in variable way the layers of the hybrid laminates, and in the case of BVBV laminate some kind of internal compensation between damage in the different layers may take place [14].

Photographs of the impact-damaged surface (those taken on the BVB laminate have been inverted for better clarity) (Figure 13) do suggest that damage appears more extended in the B-area and beyond it for VBV laminates: also, the increment of damage, passing from 15 to $22.5 \mathrm{~J}$ impact energy, is greater than for the other laminates. This consideration confirms by the comparison of the respective AE start stresses in Figure 9. In contrast, damage spreads around the whole of B-area for BVB and BVBV laminates, even at $15 \mathrm{~J}$, going considerably beyond that for $22.5 \mathrm{~J}$ impact energy, especially on BVBV laminates. This substantially confirms what has been stated, dealing with $\mathrm{AE}$ localisation data analysis, although of course some overlapping does exist, when projecting 2-D images into 1-D AE localisation graphs. It needs also to be noted for completeness that the digital inversion of images on the BVB laminates does not provide exactly the same level of contrast between damaged and undamaged parts, as it is for the direct images, so damage on these 


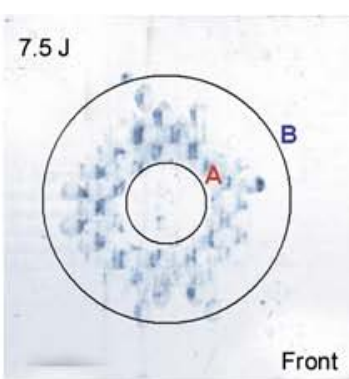

$7.5 \mathrm{~J}$

$15 \mathrm{~J}$

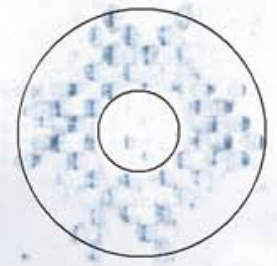

Front

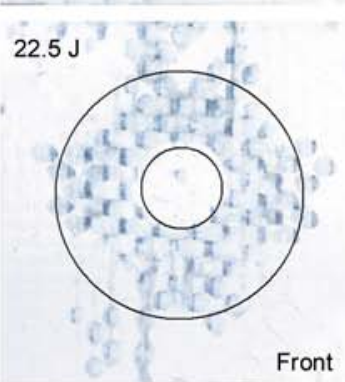

Rear

$15 \mathrm{~J}$

Rear

$22.5 \mathrm{~J}$

Rear
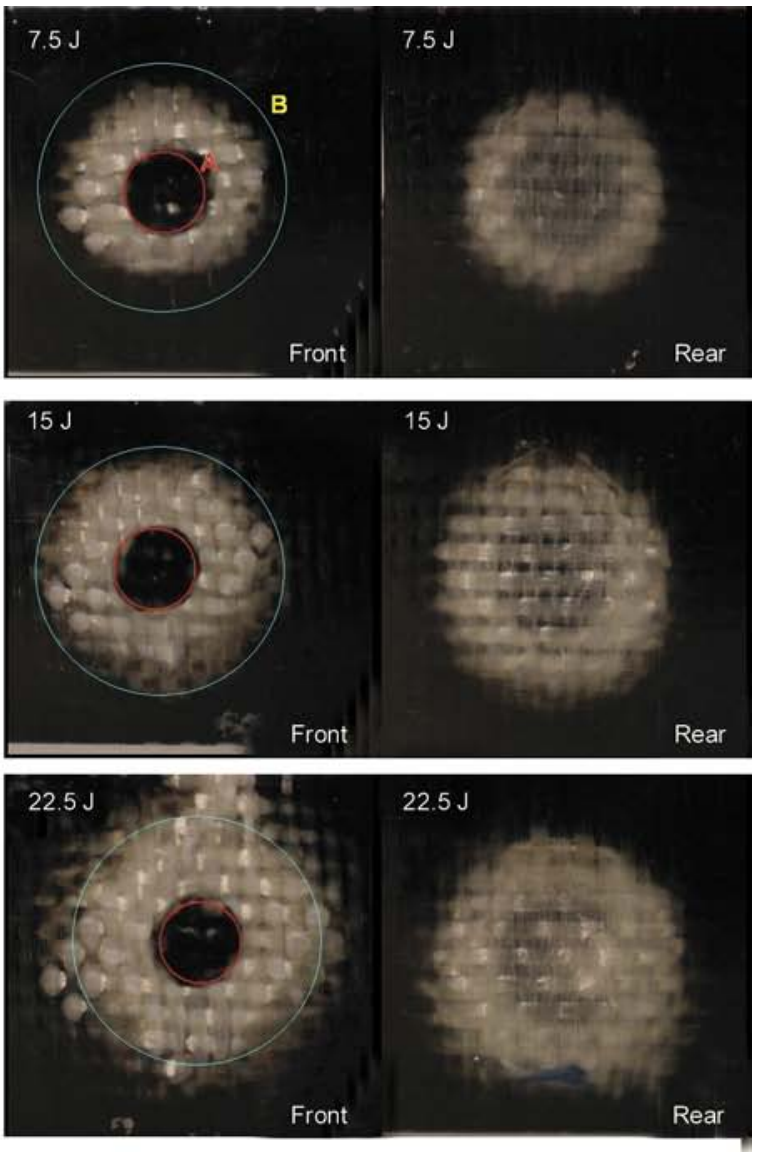
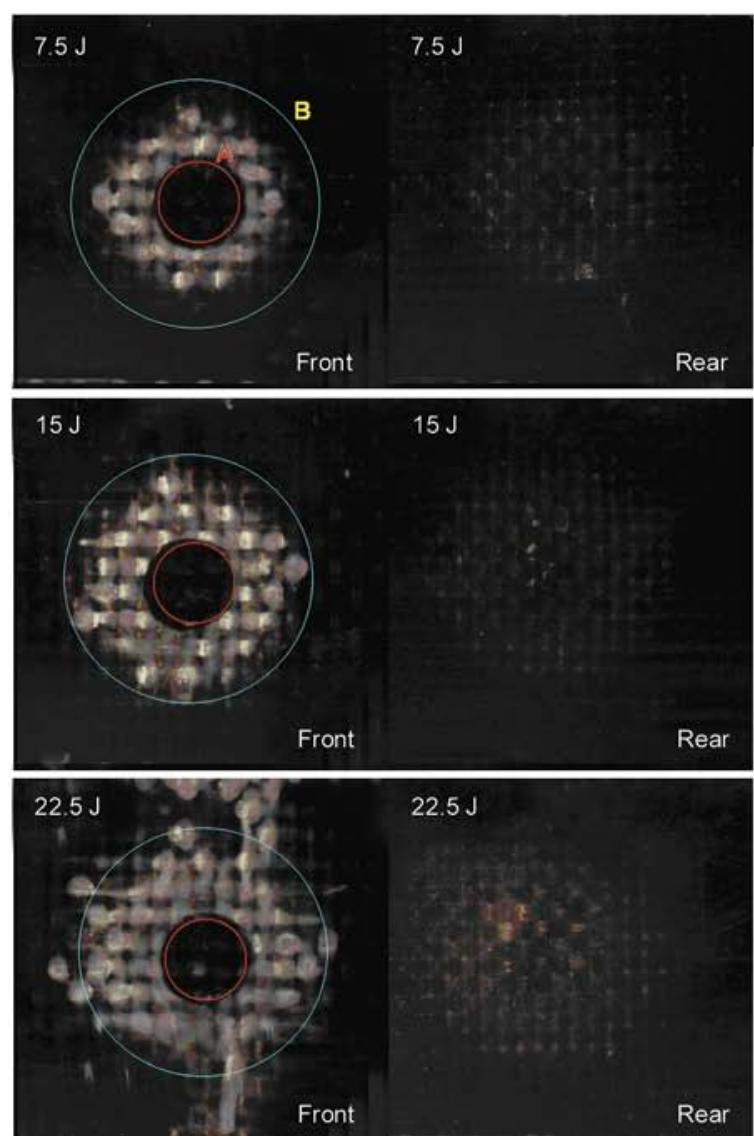

c)

Figure 13. a) Inverted value photographs of impacted BVB laminates (A and B areas are as defined for AE localisation analysis); b) Photographs of VBV laminates (A and B areas are as defined for AE localisation analysis); c) Photographs of BVBV laminates (A and B areas are as defined for AE localisation analysis) 


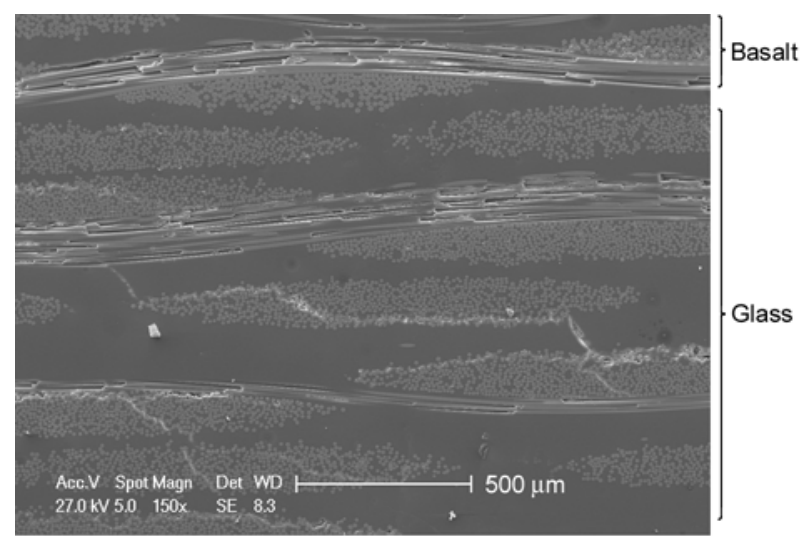

a)

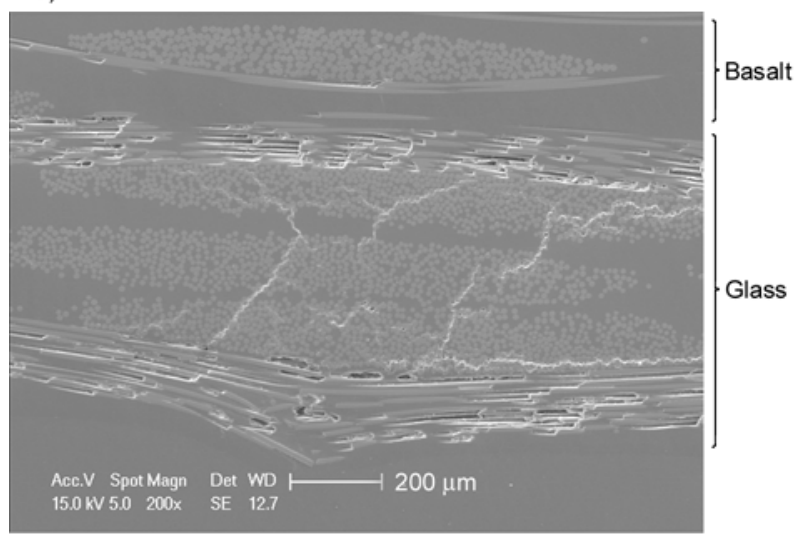

b)

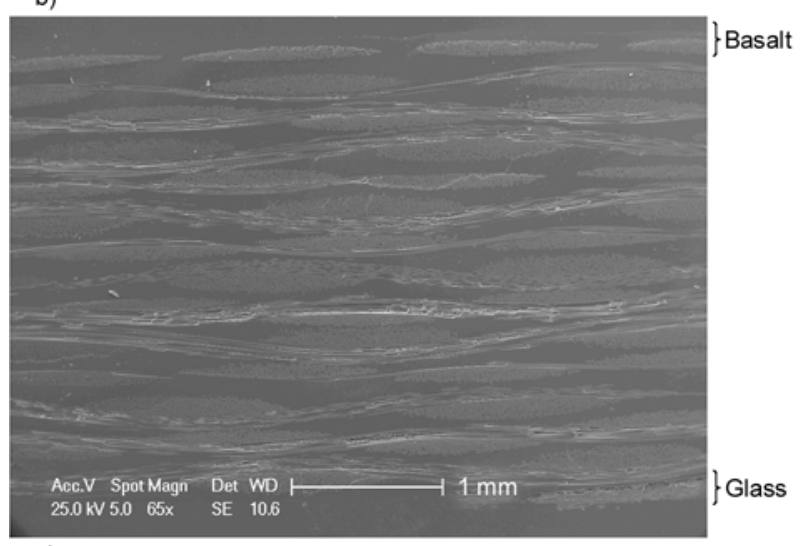

c)

Figure 14. a) Transverse section of impacted BVB laminate (impact energy $=22.5 \mathrm{~J}$ ); b) transverse section of impacted VBV laminate (impact energy = $22.5 \mathrm{~J})$; c) transverse section of impacted BVBV laminate (impact energy $=22.5 \mathrm{~J})$ (the inner layers are alternatively glass and basalt)

laminates might be slightly underestimated: however, the general sense of the statement can be confirmed.

This is substantially confirmed by SEM micrographs representing transverse sections of impacted region of all hybrid laminate configurations impacted at the highest impact energy (Figure 14). In BVB laminate most damage lies in the central glass fibre laminate (Figure 14a), whilst in the VBV laminate it is the lowest part (again a glass fibre laminate) which appears heavily damaged. In BVBV, the general appearance shows a limited presence of damage, though sometimes extended also to the basalt fibre layers (Figure 14c). It may be suggested that the presence of basalt fibre multi-layers tend to stop crack propagation, which is not the case for glass fibre ones. Post-impact residual properties of symmetrical (such as BVB and VBV) hybrid compared with intercalated hybrid (such as BVBV) laminates has been the object of a previous work on glass/jute hybrid laminates [11]. In that case, it appeared that in the intercalated hybrid laminate crack propagation is more controllable than in the superior symmetrical hybrid laminates. Due to the different nature of basalt fibre, here the perspective appears reversed, in the sense that high stiffness of basalt would sometimes allow the development of cracks in inner layers, rather than their bare compression, as it was the case with jute. Further improvement in properties is also likely to be obtained whenever using more complex systems for intercalation, which involve the combined presence of both fibres on the same layer: this has been attempted already with carbon and basalt fibres [15]. However, post-impact behaviour may be quite complex and unpredictable, and needs to be thoroughly assessed, which has not been the case so far.

\section{Conclusions}

This comparative study between different hybrid configurations based on E-glass and basalt fibre reinforced laminates confirms the slight superiority of basalt fibre woven laminates over E-glass fibre ones as for post-impact performance. It suggests furthermore that a symmetrical configuration including the lower strength material (glass) as a core for the higher strength one (basalt) presents the most favourable degradation pattern. In particular, concerns about the possible sudden collapse of the core during post-impact can be, at least in principle, overlooked. The reverse situation (basalt as core) is slightly less favourable, because it does appear less suitable to stop crack propagation, especially at impact energies approaching penetration. Further improvement of the 'as received' mechanical properties can be possibly obtained by intercalating single layers of E-glass and basalt laminates: however, 
this happens at the expense of the predictability of post-impact crack propagation. A suggestion for further work would include the investigation of intermediate structures between the one-to-one intercalated hybrids and the symmetrical ones.

\section{References}

[1] Czigány T.: Trends in fiber reinforcements - The future belongs to basalt fiber. Express Polymer Letters, 1, 59 (2007). DOI: 10.3144/expresspolymlett.2007.11

[2] De Rosa I. M., Marra F., Pulci G., Santulli C., Sarasini F., Tirillò J., Valente M.: Post-impact mechanical characterisation of glass and basalt woven fabric laminates. Composite Structures, in press (2011).

[3] Öztürk B., Aslan F., Öztürk B.: Hot wear properties of ceramic and basalt fiber reinforced hybrid friction materials. Tribology International, 40, 37-48 (2007). DOI: $10.1016 /$ j.triboint.2006.01.027

[4] Artemenko S. E., Kadykova Y. A.: Polymer composite materials based on carbon, basalt, and glass fibres. Fibre Chemistry, 40, 37-39 (2008). DOI: 10.1007/s10692-008-9010-0

[5] Wang X., Hu B., Feng Y., Liang F., Mo J., Xiong J., Qiu Y.: Low velocity impact properties of 3D woven basalt/aramid hybrid composites. Composites Science and Technology, 68, 444-450 (2008). DOI: $10.1016 /$ j.compscitech.2007.06.016

[6] Dehkordi M. T., Nosraty H., Shokrieh M. M., Minak G., Ghelli D.: Low velocity impact properties of intraply hybrid composites based on basalt and nylon woven fabrics. Materials and Design, 31, 3835-3844 (2010). DOI: $10.1016 /$ j.matdes.2010.03.033

[7] Deák T., Czigány T.: Chemical composition and mechanical properties of basalt and glass fibers: A comparison. Textile Research Journal, 79, 645-651 (2009).

DOI: $\underline{10.1177 / 0040517508095597}$
[8] Wei B., Cao H., Song S.: Environmental resistance and mechanical performance of basalt and glass fibers. Materials Science and Engineering A, 527, 4708-4715 (2010).

DOI: $10.1016 / \mathrm{j} . \mathrm{msea} .2010 .04 .021$

[9] Carmisciano S., De Rosa I. M., Sarasini F., Tamburrano A., Valente M.: Basalt woven fiber reinforced vinylester composites: Flexural and electrical properties. Materials and Design, 32, 337-342 (2011).

DOI: $10.1016 /$ j.matdes.2010.06.042

[10] Marom G., Fischer S., Tuler F. R., Wagner H. D.: Hybrid effects in composites: Conditions for positive or negative effects versus rule-of-mixtures behaviour. Journal of Materials Science, 13, 1419-1426 (1978). DOI: $10.1007 / \mathrm{BF} 00553194$

[11] De Rosa I. M., Santulli C., Sarasini F., Valente M.: Post-impact damage characterization of hybrid configurations of jute/glass polyester laminates using acoustic emission and IR thermography. Composites Science and Technology, 66, 1142-1150 (2009). DOI: $10.1016 /$ j.compscitech.2009.02.011

[12] De Rosa I. M., Santulli C., Sarasini F., Valente M.: Effect of loading-unloading cycles on impact-damaged jute/glass hybrid laminates. Polymer Composites, 30, 1879-1887 (2009). DOI: $10.1002 /$ pc.20789

[13] Meola C., Carlomagno G. M.: Impact damage in GFRP: New insights with infrared thermography. Composites Part A: Applied Science and Manufacturing, 41, 1839-1847 (2010). DOI: 10.1016/j.compositesa.2010.09.002

[14] Kowsika M. V., Mantena P. R.: Static and low-velocity impact response characteristics of pultruded hybrid glass-graphite/epoxy composite beams. Journal of Thermoplastic Composite Materials, 12, 121-132 (1999). DOI: $10.1177 / 089270579901200203$

[15] Artemenko S. E., Kadykova Y. A.: Hybrid composite materials. Fibre Chemistry, 40, 491-492 (2008).

DOI: $10.1007 / \mathrm{s} 10692-009-9091-4$ 